\title{
Outcome Predictors of Uvulopalatopharyngoplasty
}

\author{
Jae Hoon Cho \\ Department of Otorhinolaryngology-Head and Neck Surgery, Konkuk University School of Medicine, Seoul, Korea
}

\section{구개수구개인두성형술의 성공 예측인자}

\author{
조 재 훈 \\ 건국대학교 의과대학 이비인후-두경부외과학교실
}

\author{
Received February 24, 2014 \\ Accepted May 16, 2014 \\ Address for correspondence \\ Jae Hoon Cho, MD, PhD \\ Department of Otorhinolaryngology- \\ Head and Neck Surgery, \\ Konkuk University \\ School of Medicine, \\ 120-1 Neungdong-ro, Gwangjin-gu, \\ Seoul 05030, Korea \\ Tel $+82-2-2030-7667$ \\ Fax +82-2-2030-5299 \\ E-mail jaehoon@kuh.ac.kr
}

\section{서 론}

수면무호흡증 환자의 진료에서 적절한 치료법의 선택은 가 장 중요하고 어려운 과정이다. 가장 확실한 치료법으로 인정 받고 있는 지속적 양압기의 순응도는 매우 낮고, 특히 우리나 라의 경우 수술비가 저렴하기 때문에 많은 수면무호흡증 환자 들이 수술적 치료를 선호한다. ${ }^{1)}$ 수술은 과거에 치료 성공률 이 매우 낮은 것으로 간주되었으나, ${ }^{2}$ 최근의 보고에 의하면 적절히 환자를 선택할 경우 성공률을 상당히 높일 수 있으 며, 이를 위한 다양한 수술법이 소개되고 있다. ${ }^{3)}$ 이비인후과 의사의 입장에서는 수술적 치료의 성공률이 높다고 판단되 면 수술을 하고, 그렇지 못할 것 같으면 지속적 양압기나 구 강내 장치를 권유하는 것이 이상적인 수순일 것이다.

수면무호흡증의 수술적 결과를 예측하기 위한 연구들이 꾸준히 이어졌는데, 대부분은 구개수구개인두성형술에 관한 것이다. 상하악전진술은 매우 성공률이 높지만, 이환율이 높 고 수술비가 비싸 국내에서 수면무호흡증의 치료목적으로 사 용하기에는 상당한 한계가 있다.) 또한, 설근부나 하인두 수술 은 아직 널리 보급되지 않았으며, 이들 수술에 대한 대부분의
연구가 구개수구개인두성형술과 함께 시행한 결과만을 제시 하고 있어, 설근부 혹은 하인두 수술만의 효과를 분석하기가 어렵다. ${ }^{5)}$ 더욱이 대부분의 이비인후과 의사들은 구개수구개 인두성형술을 수면무호흡증의 주수술로 사용하고 있다. 따라 서 본 종설에서는 구개수구개인두성형술의 결과 예측인자들 에 대해서 정리해 보았다.

\section{탐색 방법}

Embase, PubMed, Cochrane에 검색어 "uvulopalatopharyngoplasty” 혹은 “UPPP”를 넣고 탐색하였다. 검색된 논문 들 중에서 18 세 이상의 성인을 대상으로 구개수구개인두성 형술을 시행하였고 수술 전과 후의 수면다원검사 결과가 제 시된 것만을 대상으로 하였으며, 대상자가 소아인 경우, 구개 수구개인두성형술과 다른 수술을 동시에 시행한 경우, 표준 적인 구개수구개인두성형술 외에 변형된 구개수구개인두성 형술을 사용한 경우, 구개수구개인두성형술 전과 후의 수면다 원검사 결과 없이 임상적 증상만을 평가한 경우 등은 분석에 서 제외하였다(Table 1). 수술 성공의 기준들은 조금씩 차이 
Table 1. Studies about predicting outcomes after UPPP

\begin{tabular}{|c|c|c|c|}
\hline First author & $\begin{array}{l}\text { Published } \\
\text { years }\end{array}$ & Subjects & Main findings \\
\hline$\overline{L i i^{8)}}$ & 2006 & 110 & $\begin{array}{l}\text { Success rates for mild }(90 \%) \text {, moderate }(73 \%) \text {, moderate-severe }(81 \%) \text {, and severe }(74 \%) \\
\text { patients were similar }(p=0.10) \text {. However, based on anatomical stage, success rates for } \\
\text { patients with anatomical stage I, II, III, and IV were } 100 \%, 96 \%, 65 \% \text {, and } 20 \% \text {, respec- } \\
\text { tively }(p<0.001) \text {. }\end{array}$ \\
\hline Friedman") & 2005 & 134 & $\begin{array}{l}\text { Success rates for mild, moderate, and severe patients (based on preop AHI) were very } \\
\text { similar }(33.6 \%, 29.9 \% \text {, and } 36.6 \% \text {, respectively). Based on Friedman stage, stage I had } \\
\text { a success rate of } 80.6 \% \text {, stage II had } 37.9 \% \text {, and stage III had } 8.1 \% \text {. }\end{array}$ \\
\hline Choi ${ }^{10)}$ & 2011 & 41 & $\begin{array}{l}\text { Success rates for patients who took UPPP and nasal surgery simultaneously with Friedman } \\
\text { stage I, II, and III were } 70.6 \%, 60.0 \% \text {, and } 22.2 \% \text {, respectively. }\end{array}$ \\
\hline Fukuda ${ }^{11)}$ & 1998 & 38 & $\begin{array}{l}\text { The surgical success rates based on tonsil grades 1, 2, and } 3 \text { were } 10 \%, 43 \% \text {, and } 80 \% \text {, } \\
\text { respectively, which was statistically significant. }\end{array}$ \\
\hline Soares ${ }^{13)}$ & 2012 & 34 & $\begin{array}{l}\text { For surgical failure group, lateral pharyngeal collapse }(73.3 \% \text { vs. } 36.8 \%) \text { and supraglottic } \\
\text { collapse }(93.3 \% \text { vs. } 63.2 \%) \text { were observed more frequently compared to surgical success } \\
\text { group. }\end{array}$ \\
\hline Kezirian $^{14)}$ & 2011 & 33 & $\begin{array}{l}\text { For surgical failure group, hypopharyngeal collapse was observed in the majority of } \\
\text { cases based on DISE. }\end{array}$ \\
\hline $\mathrm{Kim}^{15)}$ & 2014 & 77 & $\begin{array}{l}\text { For surgical failure group, multiple obstructions were observed after surgery based on DISE } \\
\text { (velopharynx } 100 \% \text {, oropharynx } 88 \% \text {, tongue base } 70 \% \text {, epiglottis } 44 \% \text { ). }\end{array}$ \\
\hline Aboussouan ${ }^{16)}$ & 1995 & 29 & $\begin{array}{l}\text { OSA patients with only velopharyngeal collapse based on Müller test had success rate } \\
78 \% \text {, while those with hypopharyngeal collapse had success rate } 36 \% \text {. }\end{array}$ \\
\hline $\mathrm{Li}^{17)}$ & 2003 & 28 & $\begin{array}{l}\text { Success rate for the patients with oropharyngeal obstruction only based on Müller test } \\
\text { was } 68.4 \% \text {. However, it decreased to } 22.2 \% \text { for those with both oropharyngeal and } \\
\text { hypopharyngeal obstruction. }\end{array}$ \\
\hline Friedman ${ }^{18)}$ & 2003 & 277 & $\begin{array}{l}\text { OSA patients with Friedman stage } I I \text { or III improved significantly after UPPP when } \\
\text { combined with tongue base radiofrequency ablation while patients who only had a } \\
\text { UPPP failed to improve. }\end{array}$ \\
\hline $\operatorname{Han}^{19)}$ & 2006 & 27 & $\begin{array}{l}\text { Preoperativeo AHI did not decrease significantly when tongue base obstruction was } \\
\text { observed frequently based on overnight upper airway pressure. }\end{array}$ \\
\hline $\mathrm{Li}^{20)}$ & 2013 & 79 & $\begin{array}{l}\text { Failure rate of OSA patients with hypopharyngeal obstruction was only } 11.1 \% \text { when they } \\
\text { took UPPP and tongue base surgery simultaneously. However, it increased to } 48.5 \% \\
\text { when they took UPPP only. }\end{array}$ \\
\hline Dündar ${ }^{21)}$ & 1997 & 50 & $\begin{array}{l}\text { UPPP had a higher success rate in patients with obstruction at the level of the soft palate, } \\
\text { but this rate decreased when it was associated with hypopharyngeal obstruction or } \\
\text { when there was hypopharyngeal obstruction alone. Better results were obtained when } \\
\text { UPPP was performed in patients who were young, not obese and an apnea-hypopnea } \\
\text { index was below } 40 .\end{array}$ \\
\hline Janson ${ }^{22)}$ & 1997 & 34 & $\begin{array}{l}\text { Mean preoperative AHI for surgical responders was } 25 \text { while those for non-responders } \\
\text { was } 48 \text {, while BMI was not different between them. }\end{array}$ \\
\hline Friedman ${ }^{23)}$ & 2002 & 134 & $\begin{array}{l}\text { Based on Friedman stage, stage I had a success rate of } 80.6 \% \text {, stage II had } 37.9 \% \text {, and } \\
\text { stage III had } 8.1 \% \text {. }\end{array}$ \\
\hline $\mathrm{Boot}^{24)}$ & 1997 & 60 & Neither BMI nor cephalometric measurement were surgical indicator. \\
\hline Braga $^{25)}$ & 2013 & 54 & $\begin{array}{l}\text { Variables BMI, preoperative AHI, and cephalometric measurements showed no influence } \\
\text { on surgical success. }\end{array}$ \\
\hline Shie ${ }^{26)}$ & 2013 & 117 & $\begin{array}{l}\text { Success rate of obese patients was greater than those of non-obese patients } \\
(24.6 \% \text { vs. } 62.5 \%) \text {. }\end{array}$ \\
\hline Petri ${ }^{27)}$ & 1994 & 30 & $\begin{array}{l}\text { Müller maneuver did not predict the outcome. However, lowered position of the hyoid } \\
\text { bone, increased cranio-cervical angle and shortening of the maxilla length were } \\
\text { significantly associated with poor results of UPPP. }\end{array}$ \\
\hline Millman ${ }^{28)}$ & 2000 & 46 & $\begin{array}{l}\text { Baseline } \mathrm{AHI}<38 \text {, an MP-H }<20 \mathrm{~mm} \text {, and the absence of retrognathia were predictors } \\
\text { of improvement after UPPP. }\end{array}$ \\
\hline Doghramiji ${ }^{29)}$ & 1995 & 53 & $\begin{array}{l}\text { Of all the cephalometric variables assessed, soft palate length was the only one that } \\
\text { differed between responders and nonresponders ( } 45.5 \mathrm{~mm} \text { versus } 42.6 \mathrm{~mm} \text {, } \\
\text { respectively). Müller test did not discriminate between responders and nonresponders. }\end{array}$ \\
\hline
\end{tabular}


Table 1. Studies about predicting outcomes after UPPP (continued)

\begin{tabular}{|c|c|c|c|}
\hline First author & $\begin{array}{l}\text { Published } \\
\text { years }\end{array}$ & Subjects & Main findings \\
\hline Woodson ${ }^{30)}$ & 1997 & 43 & $\begin{array}{l}\text { No cephalometric measurement predicted response to UPPP for the entire study } \\
\text { population. In the patients without retrognathia, posterior airway length was the } \\
\text { greatest predictor of response to UPPP. The distance between hyoid and mandible } \\
\text { and the maxillary-mandibular relationship were also predictive of response. }\end{array}$ \\
\hline Sher ${ }^{31)}$ & 1985 & 30 & $\begin{array}{l}\text { OSA patients with pharyngeal collapse during Müller test were most likely to respond to } \\
\text { UPPP. }\end{array}$ \\
\hline $\mathrm{Li}^{32)}$ & 2013 & 47 & $\begin{array}{l}\text { Positional OSA patients had a significantly higher success rate than nonpositional OSA } \\
\text { patients ( } 67 \% \text { vs. } 25 \%) \text {. }\end{array}$ \\
\hline van Maanen ${ }^{33)}$ & 2012 & 130 & $\begin{array}{l}\text { Surgery was not more successful in the group with position-dependent patients as } \\
\text { compared with the non-position-dependent patients. However, isolated base of } \\
\text { tongue or multilevel surgery in position-dependent OSA patients left room for } \\
\text { improvement, possibly through positional therapy. }\end{array}$ \\
\hline $\operatorname{Lee}^{34)}$ & 2010 & 69 & Mouth opening $>3.8^{\circ}$ during videofluoroscopy was a poor prognostic factor. \\
\hline
\end{tabular}

AHI: apnea-hypopnea index, OSA: obstructive sleep apnea, UPPP: uvulopalatopharyngoplasty, DISE: drug-induced sleep endoscopy, BMl: body mass index

가 있었는데, 대부분의 경우 무호흡저호흡지수가 술 전에 비 해 50\% 이상 감소하고, 술 후 무호흡저호흡지수가 20 미만인 경우로 정의하였다. ${ }^{6}$

\section{예측인자 분석}

여러 예측인자 가운데 가장 많이 다루어진 항목을 선별하 여 정리해 보았다.

\section{편도 크기}

과거 중증의 수면무호흡증 환자는 지속적 양압기를 우선 적으로 권유하고, 경도 및 중등도의 수면무호흡증 환자에게 는 수술을 시도할 수 있다고 하는 내용이 널리 퍼지면서," 마 치 무호흡저호흡지수에 근거한 분류가 수술적 결과에 지대 한 영향을 미치는 것처럼 받아들여졌지만, 실제 수술 결과들 을 분석해 보니, 무호흡저호흡지수에 의한 분류보다는 편도 크기 및 연구개의 위치 등을 고려한 해부학적 분류가 수술 성공률에 훨씬 중요하다는 사실이 알려졌다. $\mathrm{Li}$ 등 ${ }^{8}$ 이 수면 무호흡증으로 구개수구개인두성형술을 시행받은 110 명의 결 과를 분석해 보니, 경도, 중등도, 중등 및 중증, 중증군의 수 술 성공률이 각각 $90 \%, 73 \%, 81 \%, 74 \%$ 로 큰 차이가 없었으 나, 같은 환자들을 Friedman stage로 분류해 보니, stage I, II, III, IV 군의 수술 성공률이 각각 $100 \%, 96 \%, 65 \%, 20 \%$ 로 뚜렷한 차이를 보였다. Friedman 등호도 비슷한 결과를 발표하였는데, 경도, 중등도, 중증군 간에 별다른 성공률 차 이가 없었지만, Friedman stage I, II, III 군에서는 성공률이 각각 $80.6 \%, 37.9 \%, 8.1 \%$ 로 큰 차이를 보였다. 이후 발표된 Choi 등 ${ }^{10}$ 의 경우도 Friedman과 매우 흡사한 결과를 발표 하였다. 이들 연구보다 일찍 발표된 Fukuda 등ㅁㅇㅢ 연구를 보
면, 연구개나 몸무게의 고려 없이 편도 크기만을 고려한 분류 에서 편도가 grade 1 , 즉 편도가 구개궁(palatal arch)에서 겨 우 보일 정도인 경우 성공률이 $10 \%$ 로 매우 낮았지만, 편도가 중앙에서 맞닿아 있을 정도로 큰 grade 3 의 경우 $80 \%$ 에 이르 렀다. Grade 2, 즉, grade 1과 3의 중간인 경우 성공률이 $43 \%$ 였다. 이러한 결과들은 술 전에 편도가 클 경우 편도를 제거 하면 술 후 상기도가 넓어질 가능성이 많기 때문이라고 추정 된다. 다만 성인 수면무호흡증 환자들에서 편도가 큰 경우가 흔하지는 않기 때문에 예측인자로의 실효성에 의문이 있을 수 는 있겠다.

\section{하인두 폐쇄}

대부분의 수면무호흡증 환자에서 연구개 폐쇄가 발생하는 것은 잘 알려진 사실이며, ${ }^{12)}$ 구개수구개인두성형술은 주로 연 구개 폐쇄를 해결하기 위해 시행된다. 따라서 설근부를 포함 한 하인두 폐쇄가 동반된 수면무호흡증 환자들의 경우 구개 수구개인두성형술 후 결과가 좋지 않을 것이라는 추정이 가 능하다. 실제 이를 뒷받침하는 연구 결과들이 많다. Soares 등 $^{13)}$ 은 수술 실패군은 성공군에 비해 술 전 약물유도 수면내 시경검사에서 성문상부 폐쇄가 많이 관찰되었다고 하였으며, $\operatorname{Kezirian}^{14}$ 과 $\operatorname{Kim}_{\text {등 }}{ }^{15}$ 은 수술 실패군의 경우 대부분 술 후에 하인두 폐쇄가 관찰된다고 하였다. Aboussouan 등 ${ }^{16)}$ 에 의하 면 Muiller test에서 연인두문 협착(velopharyngeal collapse) 만 있는 경우 $78 \%$ 의 수술 성공률을 보인 반면, 하인두 협착이 동반된 경우 $36 \%$ 로 떨어졌다. $\mathrm{Li}$ 등 ${ }^{17)}$ 의 경우 수면내시경을 사용하여 관찰한 결과 구인두 폐쇄만 있는 경우 술 전 무호 흡저호흡지수가 48.6에서 술 후 18.7로 감소하였으나, 하인두 폐쇄가 동반된 경우 술 전 무호흡저호흡지수가 53.0에서 술 후 34.0으로 감소폭이 적었다고 보고하였다. Friedman 등 ${ }^{18)}$ 
은 설근부가 크지 않은 Friedman stage II 환자군의 경우에 는 구개수구개인두성형술만 시행해도 술 후 무호흡저호흡지 수가 의미 있게 감소하였으나, 설근부가 큰 stage III 환자군 의 경우 구개수구개인두성형술만으로는 무호흡저호흡지수가 의미 있게 감소하지 않고 설근부에 고주파 수술을 동시에 시 행해야 의미 있게 감소하였다고 보고하였다. Han 등 19 은 하룻 밤 동안 상기도 압력을 측정해 보니 설근부 폐쇄가 많은 경 우 술 후 무호흡저호흡지수 호전이 적었다고 보고하였다. $\mathrm{Li}$ 등 $^{20)}$ 은 술 전에 비인두관을 삽입해도 무호흡저호흡지수가 15 이상이며, 컴퓨터단층촬영에서 후설부(retrolingual space)가 좁은 환자들에 대해서 구개수구개인두성형술과 더불어 설근 부 협착을 막아준다고 알려진 Repose system ${ }^{\circledR}$ (Medtronic, Fridley, MN, USA)을 사용한 경우 실패한 경우가 $11.1 \%$ 에 불 과하지만, 구개수구개인두성형술만 시행한 경우 $48.5 \%$ 에 이 르렀다고 보고하였다. 이런 결과들을 종합해 보면, 설근부를 포함한 하인두 폐쇄가 있는 경우 구개수구개인두성형술만으 로 좋은 결과를 기대하기 어려울 것이라고 예상된다.

\section{술 전 무호흡저호흡지수}

앞에서 언급했듯이, 과거 술 전 무호흡저호흡지수가 높으 면 수술 결과가 좋지 않다는 주장이 있었으낙) 그 이후 술 전 무호흡저호흡지수의 여부보다는 편도 크기 등 해부학적 특 징이 더 중요하다는 연구들이 많이 발표되었다. 연구 초기에 Dündar 등 ${ }^{21)}$ 의 경우 술 전 무호흡저호흡지수가 40이 넘은 경우 예후가 좋지 않다고 발표하였고 비슷한 시기에 Janson 등 22 도 구개수구개인두성형술의 반응군은 평균 술 전 무호흡 저호흡지수가 25임에 반해, 비반응군의 경우 48 로 매우 높았 다고 발표해 술 전 무호흡저호흡지수가 높을수록 수술적 예 후가 좋지 않다는 믿음이 팽배하였으나, 이후 Friedman 등," $\mathrm{Li}$ 등이이 앞서 제시한 연구들에서 술 전 무호흡저호흡지수가 별다른 의미가 없다고 주장하였다. 하지만, 그 이후에도 엇갈 린 주장들이 발표되고 있다.

\section{비만도}

일반적으로 비만한 경우 상기도 내경이 좁아지므로 수면무 호흡증이 심해지고 술 후에도 예후가 좋지 않을 것으로 예상 된다. Friedman 등 ${ }^{23}$ 의 경우도 해부학적 구조에 의한 stage 를 만들면서 체질량지수가 40이 넘는 경우 다른 해부학적 특 징을 무시하고 가장 높은 stage IV라고 정의해 비만도가 강력 한 예측인자임을 암시하였다. 하지만 Boot 등 ${ }^{24)}$ Janson 등,2) Braga 등 25)은 체질량지수가 수술 결과와 관련이 없다고 하였 고, Dündar 등, ${ }^{21)}$ Shie 등 ${ }^{26)}$ 은 관련이 있다고 하여 서로 상반 된 결과를 보였다.

\section{두개골 계측법(Cephalometry)}

전체적인 측면 상기도의 구조 및 주변 골구조도 파악할 수 있는 두개골 계측법은 수면무호흡증 연구 초반부터 꾸준히 사용되었다. 많은 연구자들이 이를 분석하여 수술에 영향을 주는 특징을 발견하려 노력하였는데, Petri 등 27$)$ 은 설골이 낮 은 경우, 경추각(craniocervical angle)이 증가한 경우, 상악골 이 짧은 경우 예후가 좋지 않다고 했고, Millman 등ㄹ)은 하악 의 하연과 가장 좁은 인두부 기도부위를 연결한 선에서 설골 까지의 거리가 $21 \mathrm{~mm}$ 이하인 경우 예후가 좋다고 하였다. 하 지만, 그 후 Doghramji 등, ${ }^{29)}$ Boot 등, ${ }^{24)}$ Woodson과 Conley, ${ }^{30)}$ Braga 등 ${ }^{25)}$ 은 별다른 예측인자를 발견하지 못하였다.

\section{Müller test}

각성상태에서 역발살바(reverse Valsalva)를 시행해 관찰되 는 폐쇄부위를 수면 시 폐쇄가 일어나는 부위로 추정하는 Müller test는 수면무호흡증 연구 초반에 상당히 의미 있는 방법으로 인정받았다. ${ }^{12)}$ Sher 등 ${ }^{31)}$ 은 Müller test에서 인두 폐 쇄가 관찰된 경우 구개수구개인두성형술의 좋은 예측인자로 평균 무호흡저호흡지수가 술 후 $72 \%$ 감소한다고 발표하였고, Aboussouan ${ }^{13)}$ 은 연인두문 협착만 있는 경우 구개수구개인 두성형술 성공률이 $78 \%$ 인 반면, 하인두 협착이 있는 경우 성 공률이 $36 \%$ 로 떨어진다고 하였다. 하지만 그 이후 Petri 등 ${ }^{27)}$ Doghramji 등, ${ }^{29}$ Boot 등 ${ }^{24}$ 은 Müller test가 별다른 의미가 없 었다고 발표하였다.

\section{자세 의존성}

자세 의존성(position dependency)이란 앙와위 자세에서 의 무호흡저호흡지수가 비앙와위 자세에서의 무호흡저호흡 지수에 비해 2배 이상 큰 경우인데, $\mathrm{Li}$ 등 ${ }^{32}$ 은 자세 의존성이 있는 경우 수술 성공률이 67\%인 반면, 그렇지 않은 경우 $25 \%$ 였다고 주장하였다. 하지만, van Maanen 등 33 은 별다른 관련 성이 없다고 하였다.

\section{입 벌림(Mouth opening)}

Lee 등 ${ }^{34)}$ 은 수면 중 동영상투시법검사(videofluoroscopy) 에서 3.8도 이상의 입 벌림이 있으면 실패확률이 매우 높다고 주장하였다.

\section{맺 음 말}

구개수구개인두성형술의 수술 결과를 예측할 때 가장 관 심을 가져야 할 항목은 편도의 크기와 하인두 폐쇄 여부이 다. 편도가 클수록 결과가 좋고, 하인두 폐쇄가 관찰되면 예 
후는 좋지 않다. 술 전 무호흡저호흡지수와 체질량지수, 자세 의존성 등에 대해서는 상반된 연구결과들이 있어 아직 명확 한 결론을 내리기 어렵고, 추가적인 연구가 필요하다. 두개골 계측법과 Muiller test는 술 후 성공률을 예측하는 검사로서 효용성이 낮다.

\section{REFERENCES}

1) Choi JM, Jung H, Shin DH, Kim YW, Kim JK, Hong SC, et al. Survey of continuous positive airway pressure use in Korea. J Rhinol 2012; 19(2):107-11.

2) Sher AE, Schechtman KB, Piccirillo JF. The efficacy of surgical modifications of the upper airway in adults with obstructive sleep apnea syndrome. Sleep 1996;19(2):156-77.

3) Powell NB. Contemporary surgery for obstructive sleep apnea syndrome. Clin Exp Otorhinolaryngol 2009;2(3):107-14.

4) Li KK, Powell NB, Riley RW, Troell RJ, Guilleminault C. Long-Term Results of Maxillomandibular Advancement Surgery. Sleep Breath 2000;4(3):137-40

5) Kezirian EJ, Goldberg AN. Hypopharyngeal surgery in obstructive sleep apnea: an evidence-based medicine review. Arch Otolaryngol Head Neck Surg 2006;132(2):206-13.

6) Megwalu UC, Piccirillo JF. Methodological and statistical problems in uvulopalatopharyngoplasty research: a follow-up study. Arch Otolaryngol Head Neck Surg 2008;134(8):805-9.

7) Aurora RN, Casey KR, Kristo D, Auerbach S, Bista SR, Chowdhuri $\mathrm{S}$, et al. Practice parameters for the surgical modifications of the upper airway for obstructive sleep apnea in adults. Sleep 2010;33 (10):1408-13.

8) Li HY, Wang PC, Lee LA, Chen NH, Fang TJ. Prediction of uvulopalatopharyngoplasty outcome: anatomy-based staging system versus severity-based staging system. Sleep 2006;29(12): 1537-41.

9) Friedman M, Vidyasagar R, Bliznikas D, Joseph N. Does severity of obstructive sleep apnea/hypopnea syndrome predict uvulopalatopharyngoplasty outcome? Laryngoscope 2005;115(12): 2109-13.

10) Choi JH, Kim EJ, Cho WS, Kim YS, Choi J, Kwon SY, et al. Efficacy of single-staged modified uvulopalatopharyngoplasty with nasal surgery in adults with obstructive sleep apnea syndrome. Otolaryngol Head Neck Surg 2011;144(6):994-9.

11) Fukuda $N$, Abe T, Katagiri M, Yokoba $M$, Okamoto M, Tomita $T$. [Effects of uvulopalatopharyngoplasty on patients with obstructive sleep apnea--the severity of preoperative tonsillar hypertrophy]. Nihon Kokyuki Gakkai Zasshi 1998;36(1):34-40.

12) Cho JH. Evaluation of obstruction site in obstructive sleep apnea. Korean J Otorhinolaryngol-Head Neck Surg 2012;55(11):681-5.

13) Soares D, Sinawe H, Folbe AJ, Yoo G, Badr S, Rowley JA, et al. Lateral oropharyngeal wall and supraglottic airway collapse associated with failure in sleep apnea surgery. Laryngoscope 2012;122(2):473-9.

14) Kezirian EJ. Nonresponders to pharyngeal surgery for obstructive sleep apnea: insights from drug-induced sleep endoscopy. Laryngoscope 2011;121(6):1320-6.

15) Kim DK, Lee JW, Lee JH, Lee JS, Na YS, Kim MJ, et al. Drug induced sleep endoscopy for poor-responder to uvulopalatopharyngoplasty in patient with obstructive sleep apnea patients. Korean J Otorhinolaryngol-Head Neck Surg 2014;57(2):96-102.

16) Aboussouan LS, Golish JA, Wood BG, Mehta AC, Wood DE, Dinner DS. Dynamic pharyngoscopy in predicting outcome of uvulopalatopharyngoplasty for moderate and severe obstructive sleep apnea. Chest 1995;107(4):946-51.

17) Li W, Ni D, Jiang H, Zhang L. [Predictive value of sleep nasendoscopy and the Müller maneuver in uvulopalatopharyngoplasty for the obstructive sleep apnea syndrome]. Lin Chuang Er Bi Yan Hou Ke Za Zhi 2003;17(3):145-6.

18) Friedman M, Ibrahim H, Lee G, Joseph NJ. Combined uvulopalatopharyngoplasty and radiofrequency tongue base reduction for treatment of obstructive sleep apnea/hypopnea syndrome. Otolaryngol Head Neck Surg 2003;129(6):611-21.

19) Han DM, Ye JY, Li YR, Zhang YH, Wang XY, Yin GP, et al. [Preoperative overnight airway pressure measurement for predicting the outcome of revised uvulopalatopharyngoplasty]. Zhonghua Er Bi Yan Hou Tou Jing Wai Ke Za Zhi 2006;41(10):753-8.

20) Li SH, Wu DH, Bao JM, Shi HJ. Outcomes of upper airway reconstructive surgery for obstructive sleep apnea syndrome based on polysomnography after nasopharyngeal tube insertion. Chin Med J (Engl) 2013;126(24):4674-8.

21) Dündar A, Gerek M, Ozünlü A, Yetiser S. Patient selection and surgical results in obstructive sleep apnea. Eur Arch Otorhinolaryngol 1997;254 Suppl 1:S157-61.

22) Janson $C$, Gislason $T$, Bengtsson $H$, Eriksson G, Lindberg E, Lindholm CE, et al. Long-term follow-up of patients with obstructive sleep apnea treated with uvulopalatopharyngoplasty. Arch Otolaryngol Head Neck Surg 1997;123(3):257-62.

23) Friedman M, Ibrahim H, Bass L. Clinical staging for sleep-disordered breathing. Otolaryngol Head Neck Surg 2002;127(1):13-21.

24) Boot H, Poublon RM, Van Wegen R, Bogaard JM, Schmitz PI, Ginaï AZ, et al. Uvulopalatopharyngoplasty for the obstructive sleep apnoea syndrome: value of polysomnography, Mueller manoeuvre and cephalometry in predicting surgical outcome. Clin Otolaryngol Allied Sci 1997;22(6):504-10.

25) Braga A, Grechi TH, Eckeli A, Vieira BB, Itikawa CE, Küpper DS, et al. Predictors of uvulopalatopharyngoplasty success in the treatment of obstructive sleep apnea syndrome. Sleep Med 2013;14(12):1266-71.

26) Shie DY, Tsou YA, Tai CJ, Tsai MH. Impact of obesity on uvulopalatopharyngoplasty success in patients with severe obstructive sleep apnea: a retrospective single-center study in Taiwan. Acta Otolaryngol 2013;133(3):261-9.

27) Petri N, Suadicani P, Wildschiødtz G, Bjørn-Jørgensen J. Predictive value of Müller maneuver, cephalometry and clinical features for the outcome of uvulopalatopharyngoplasty. Evaluation of predictive factors using discriminant analysis in 30 sleep apnea patients. Acta Otolaryngol 1994;114(5):565-71.

28) Millman RP, Carlisle CC, Rosenberg C, Kahn D, McRae R, Kramer NR. Simple predictors of uvulopalatopharyngoplasty outcome in the treatment of obstructive sleep apnea. Chest 2000;118(4):1025-30.

29) Doghramji K, Jabourian ZH, Pilla M, Farole A, Lindholm RN. Predictors of outcome for uvulopalatopharyngoplasty. Laryngoscope 1995;105(3 Pt 1):311-4.

30) Woodson BT, Conley SF. Prediction of uvulopalatopharyngoplasty response using cephalometric radiographs. Am J Otolaryngol 1997;18(3):179-84.

31) Sher AE, Thorpy MJ, Shprintzen RJ, Spielman AJ, Burack B, McGregor PA. Predictive value of Müller maneuver in selection of patients for uvulopalatopharyngoplasty Laryngoscope 1985;95(12): $1483-7$.

32) Li HY, Cheng WN, Chuang LP, Fang TJ, Hsin LJ, Kang CJ, et al. Positional dependency and surgical success of relocation pharyngoplasty among patients with severe obstructive sleep apnea. Otolaryngol Head Neck Surg 2013;149(3):506-12.

33) van Maanen JP, Ravesloot MJ, Witte BI, Grijseels M, de Vries N. Exploration of the relationship between sleep position and isolated tongue base or multilevel surgery in obstructive sleep apnea. Eur Arch Otorhinolaryngol 2012;269(9):2129-36.

34) Lee CH, Mo JH, Seo BS, Kim DY, Yoon IY, Kim JW. Mouth opening during sleep may be a critical predictor of surgical outcome after uvulopalatopharyngoplasty for obstructive sleep apnea. J Clin Sleep Med 2010;6(2):157-62. 